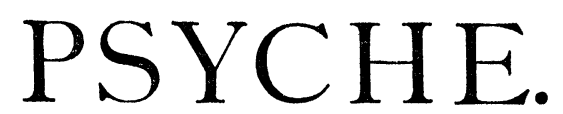

ORGAN OF THE CAMBRIDGE ENTOMOLOGICAL CLUB EDITED BY B. PICKMAN MANN.

Vol. I.] Cambridge, Mass., October, 1875. [No. 18.

\title{
The Chirp of the Mole-cricket.
}

The common mole-cricket of the United States (Gryllotalpa borealis Burm.) usually commences its daily chirp at about four o'clock in the afternoon, but stridulates most actively at about dusk. On a cloudy day, however, it may be heard as early as two or three o'clock; this recognition of the weather is rather remarkable in a burrowing insect, and the more so since it does not appear to come to the surface to stridulate, but remains in its burrow usually an inch below the surface of the ground. The European mole-cricket is said to chirp both within its burrow and at its mouth (plerumque sub terrâ, Fischer says), and it may be that our species sometimes seeks the air in chanting; but the chirp, as far as I have heard it, always has a uniformly subdued tone, as if produced in some hidden recess. Fischer says that the European species, which is twice as large as ours, cannot be heard more than from one hundred and fifty to two hundred feet (ultra spatium 20-30 passuum). Ours, when certainly beneath the surface, is easily distinguished at a distance of five rods; and one would presume that it could be heard, if above ground, nearly twice as far away.

Its chirp is a guttural sort of sound, like grï or grēēu, repeated in a trill indefinitely, but seldom for more than two or

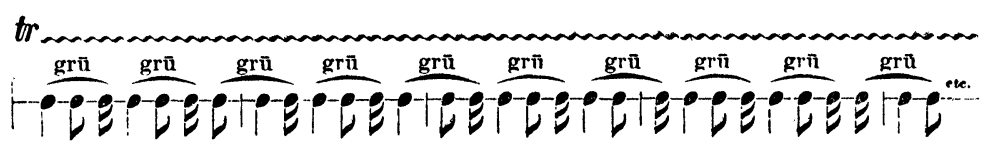

three minutes, and often for a less time. It is pitched at two octaves above middle $\mathrm{C}$, and the notes are usually repeated at the rate of about 130 or 135 per minute: sometimes, when many are singing, even as rapidly as 150 per minute. Often, 
when it first commences to chirp, it gives a single prolonged trill of more slowly repeated notes, when the composite character of the chirp is much more readily detected; and afterward is quiet for a long while. When most actively chirping, however, the commencement of a strain is less vigorous than its full swell, and the notes are then repeated at the rate of about 120 per minute; it speedily gains its normal velocity. The note sounds exceedingly like the distant croak of toads (Bufo) at spawning season, but is somewhat feebler. Zetterstedt compares the chirp of the European species to the note of Hyla arborea.

Although belonging to the saltatorial Orthoptera, this insect, like the other species of its genus, is a poor leaper ; inepte salit says Fischer of its European congener. But on the other hand, it can run backward quite as easily as forward,- a fortunate gift, as the greater part of its burrow is too narrow for it to turn in.

Samuel H. Scudder.

\section{Hibernation of Amphipyra pyramidoides.}

In Vol. VI, No. 2, of the Canadian Entomologist, the Editor, in speaking of Amphipyra pyramidoides, says : "In what stage of its existence this insect passes the winter months, has not yet been determined. Whether the eggs, which are probably laid during August, remain dormant during the remainder of the summer and hatch early in the following spring, or whether the eggs hatch into larvæ early in the fall, and the larvæ, while still young, become torpid and sleep through the long winter months, remains undecided; we incline, however, to the latter view."

Observations that $I$ have at different times made upon the habits of this moth, would lead to a different conclusion. While collecting Catocalas during August (1874) in Weston, Mass., I several times struck dead trees and raised a cloud of $A$. pyramidoides which flew out from under the loose bark. Tearing off the bark, I found hundreds of them, many living and some mere mouldy skeletons. I paid no particular attention to the fact at first, but afterwards, finding many trees inhabited in this manner, not only during the autumn, but also 

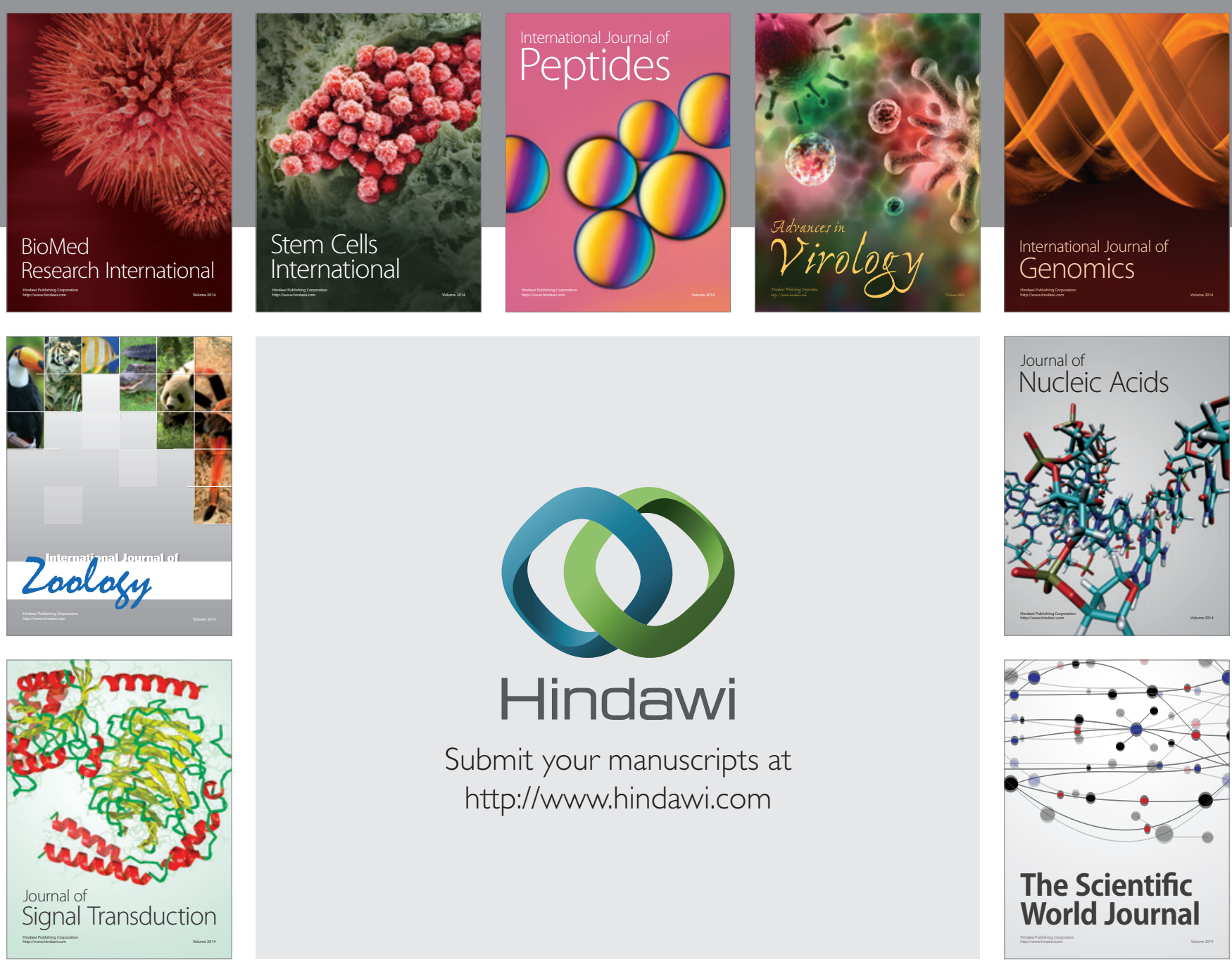

Submit your manuscripts at

http://www.hindawi.com
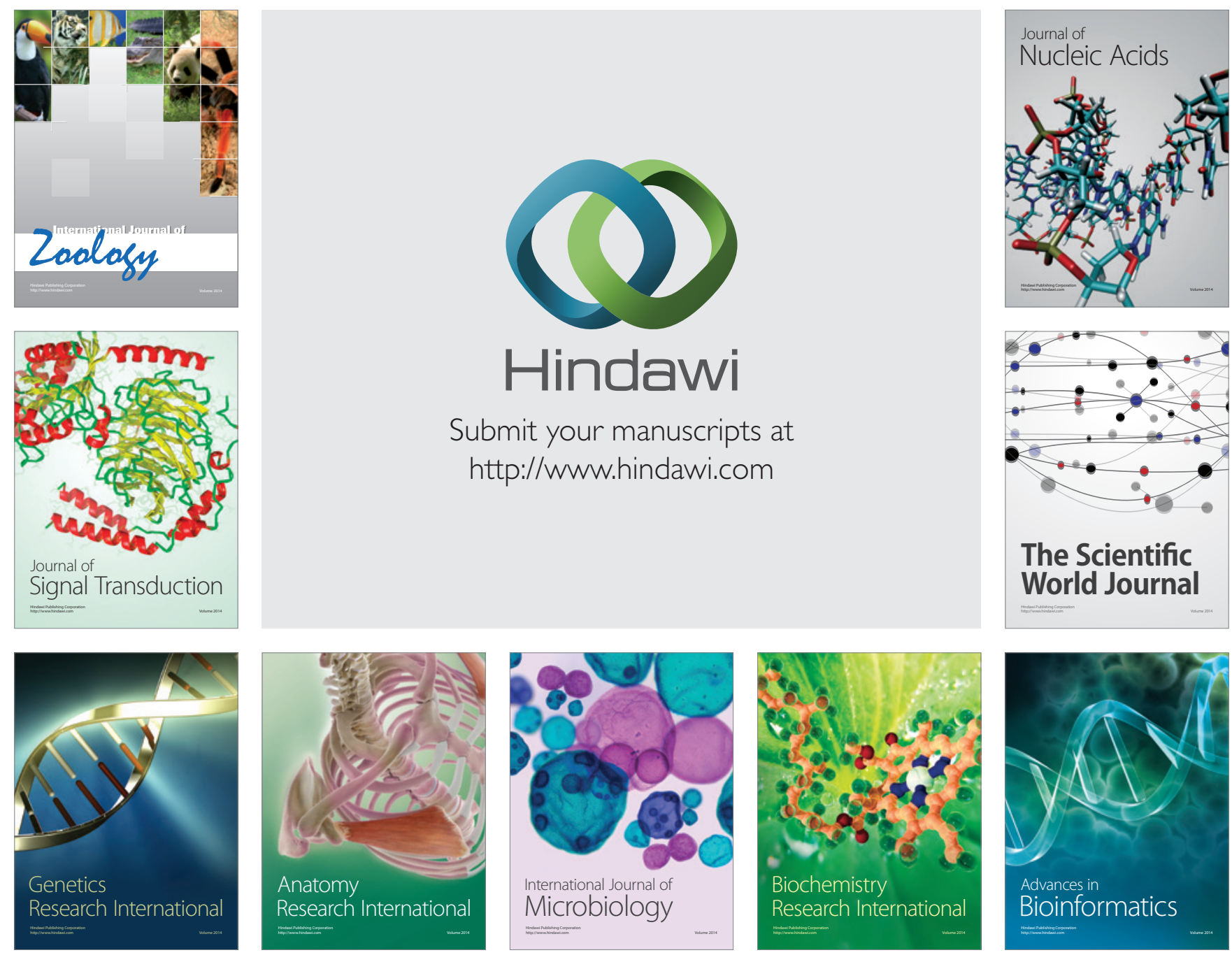

The Scientific World Journal
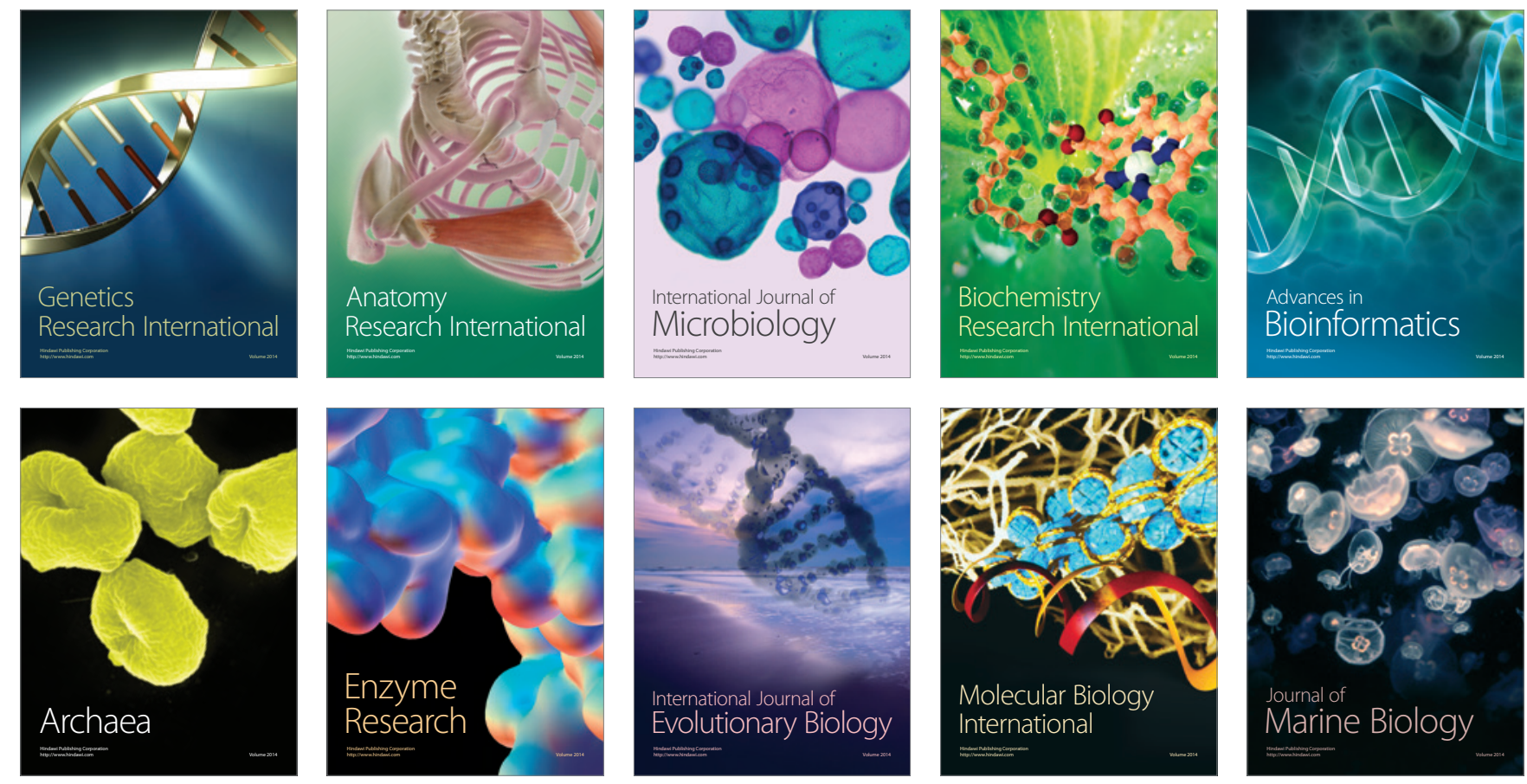